\title{
Influence of water absorption on glass fibre reinforced IPN composite pipes
}

\author{
Suresh Gopi ${ }^{1 *}$ (D), Ganesh Babu Loganathan², Bharani Kumar Sekar¹, Rajesh Kanna Krishnamoorthy', \\ Vivek Sekaran ${ }^{1}$ and Akash Rajendran Mohan ${ }^{1}$
${ }^{1}$ Department of Mechanical Engineering, Rajalakshmi Institute of Technology, Chennai, India ${ }^{2}$ Department of Mechatronics Engineering, ISHIK International University, Iraq
*saisuresh1979@gmail.com

\begin{abstract}
Glass fibre reinforced composite pipes were fabricated by using an IPN blend of $0 \%, 10 \%, 20 \%, 30 \%, 40 \%, 50 \%$ PU prepolymer (Polyurethane) with VER(Vinylester) resin. The prepared IPN (Interpenetrating polymer networks) composite pipes were subjected to boiling water immersion tests in order to study the effect of moisture absorption characteristics. The Burst strength and Hoop strength of water immersed specimens were evaluated (3, 6, 9, 12 months) and compared along with dry composite specimens. It was found that, percentage of moisture uptake was significantly reduced with increase in PU loading into the IPN system as well the Burst strength and Hoop strength of the specimens were found to be diminishing with raise in percentage of moisture uptake and raise in temperature; contrarily, the addition of PU significantly reduced the moisture intake, in addition to that the PU added IPN pipe offers better mechanical strength while compared with neat Vinylester pipes.
\end{abstract}

Keywords: interpenetrating polymer networks, vinylester, polyurethane, hygrothermal, GFRP pipes.

How to cite: Gopi, S., Loganathan, G. B., Sekar, B. K., Krishnamoorthy, R., K., Sekaran, V., \& Mohan, A. R. (2019). Influence of water absorption on glass fibre reinforced IPN composite pipes. Polimeros: Ciência e Tecnologia, 29(3), e2019038. https://doi.org/10.1590/0104-1428.02818

\section{Introduction}

Nowadays glass fibre reinforced polymer composite materials have been very extensively used in most of the application like manufacturing of pipes, tanks and other products used in humid conditions. In general GFRPs normally have more durability when compared with other types of conventional material ${ }^{[1]}$. It provides high strength, chemical stability, stiffness to weight ratio, chemical resistance and have the ability to be tailored for different requirements ${ }^{[2]}$.

More over the GRP Pipes are often considered as an alternative to conventional metallic pipes where corrosion, environmental effect and weight limit are considered. Whenever these pipes are subjected to hygrothermal conditions, it absorbs moisture from the surrounding environment ${ }^{[3]}$. This kind of frequent moisture uptake has played an important influence on the mechanical strength of these materials. Apart from that environmental factors are also very much important when the GFRP are exposed to moist environments in order to forecast their long term properties ${ }^{[4]}$. Complex phenomenon like plasticizing effect of the matrix, rearrangement of the chemical structure, de-bonding might occur on GFRP when they come across hygrothermal environment. The strength between the fibre-matrix (interface) also degraded in the high temperature environment. It has been concluded that rather than creating diffusion through the matrix (plasticization), the moisture diffuse itself more easily along the fibre and destroy the fibre-matrix interface. Although the fibre-matrix interface plays a crucial role in strength by load transferring, without a tough bond at the interface sometimes the matrix strength dominate in all environments ${ }^{[5]}$. Normally the water absorption by the matrix takes place by capillarity action along the fibre-matrix interface, through some cracks, void present in the resin. Many diffusion models have been predicted over the years to model the hygrothermal effect in FRP pipes. The first diffusion model has been proposed by Fick, by the analogy of heat conduction model. Most of the researchers completely rely on Fick's second law to find out the moisture absorption models ${ }^{[6-8]}$. The rapid study and development in the area of GFRP manufacturing promulgates to understand the behavioral change of the material in different environmental conditions in order to certify for their long-term durability. Hence, the new product needs numerous investigations to make sure their sustainability in different hygrothermal conditions by comparing dry and aged specimens. Moreover, polymeric matrix material often plasticized, swelled and softenend when subjected into hygrothermal environment. The primary degradation or deterioration of polymeric resin leads to weak interface bond between the fibre-resin bonds ${ }^{[9,10]}$.

Among all kind of thermoset resins, vinylester (VER) resins are widely used and considered as the best one 
kind of thermoset resin in the area of pipe, tanks, ducts manufacturing. Because vinylester resins have the combined properties of epoxies and unsaturated polyesters. They possess better chemical resistance than all kind of polyester resins. Basically vinylester resin are based on the reactant group of an epoxy and ethylenically unsaturated carboxylic acid, which adversely result in a polymer with chain of end unsaturation. The mechanical strength mainly depends on the structure of the matrix resins, properties of fibres, volumetric fraction of fibres (Vf) and interphase strength ${ }^{[11-13]}$.

Similarly another class matrix material was polyurethane (PU), famous in the field of rubber cum coating industry for their adaptable, versatile and attractive properties. It possess very good abrasion resistance property, tear strength, shock absorption property and renowned for their elastic property ${ }^{[14,15]}$. These kinds of polymer are generally used as adhesives, coatings for infrastructural applications as well as used as matrix resin for composite manufacturing. Besides that, it has a very good (low viscosity) processability and excellent bonding characteristics with different substrates. Moreover, when polyurethanes are subjected into hygrothermal environment, it undergoes plasticizing effect by degrading it, this was because of the intrusion of the water into the free volume of the polymer during absorption. The splintering of the hydrogen bond intrachains also reason behind that of the plasticizing effect (increase in mobility chain macromolecular) of the polyurethane. Hence with exclusive properties of both the resins, a special class of polymer blend matrix material has been formed, which is called as interpenetrating polymer networks (IPNs). Instead of spending valuable time in the area of altering the chemistry of the styrene and other functional group of vinylester polymer, a blend of mixing of two or more polymers to extract specific superior quality of individual polymers has been carried out. This kind of blends does not chemically react with each other rather it maintains the mutual entanglement between two of them ${ }^{[16,17]}$.

\section{Experimental}

\subsection{Materials}

Vinyl ester resin VBR 4508 used in this study was procured from Vasavi Bala Resins (P) Ltd. Chennai. Polyurethane (CG-60A Commercial Grade based on TDI System) was provided by Cross Link Technology. The E-glass fibre used in this study was plain - woven mat ( 350 gsm). All chemicals were used as purchased.

\subsection{Sample preparation}

\subsubsection{VER/PU blend preparation}

The ratio of polyurethane (Polyether polyol) pre polymer (PU) and hardener was 100:7 (mocca - methylene bis-ortho chloroaniline) wt/wt was taken initially. The entire mixture was kept in the degassing chamber for a period of 5 minutes till most of the bubbling got ceased. Following that, Vinylester (VER) was added with cobalt naphthenate accelerator, promoter and catalyst as per the manufacturer recommendation of $100 / 2 / 2 / 2$. Both the resins were thoroughly mixed ${ }^{[6-8]}$.

\subsubsection{Fabrication of composite pipes}

The IPN pipes were fabricated by hand lay-up technique. First, the mandrel with the diameter of $124 \mathrm{~mm}$ was placed over the two steel roller supports as shown in the Figure 1. Secondly the mandrel was wetted with the releasing agent, before the coating of IPNs. Thirdly surface mat was wounded over the entire circumference of the mandrel in order to get the glossy surface finish inside the pipe as shown in Figure 2. Following this plain woven fabric $(350 \mathrm{gsm})$ was wounded over the entire mandrel after wetting the surface mat with IPN blend. This wounding process was continued until an average thickness of $3 \mathrm{~mm}$ was obtained.

Besides that the pipe was post cured at $80^{\circ} \mathrm{C}$ for 2 hours, after it was removed from the mandrel. All the samples were subjected to visual inspection method in order to find out the scratches, flaws, voids and other imperfections. The pipes were made with different proportions of blends with VER and PU as per the Table 1 .

The total length of the final composite pipe was one meter. With help of the special saw, the composite pipe was cut into different specifications according ASTM D 570, ASTM D1599 \& ASTM D2290 standards. Utmost care was given in order to avoid the cutting edge effects. In addition to that the following defects were avoided in the specimens at the cutting edges, like air bubble, accumulation of resin,

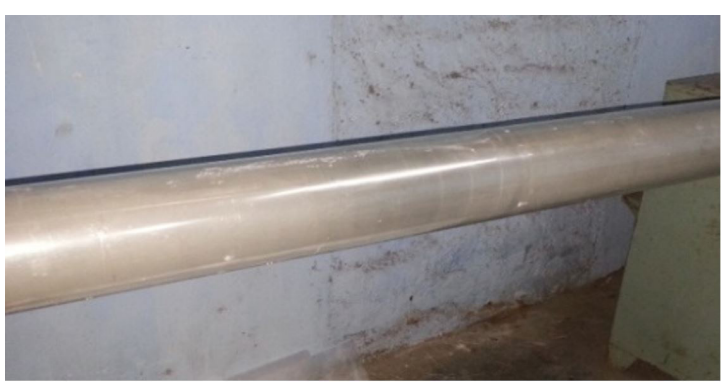

Figure 1. Terphane releasing film wounded mandrel.

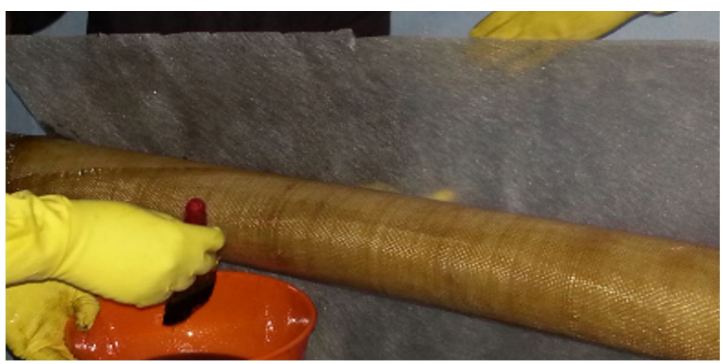

Figure 2. Wrapping of surface mat

Table 1. Typical combination of IPN - Formulation.

\begin{tabular}{ccc}
\hline Sample. No & VER $(\mathbf{g})$ & PU (g) \\
\hline 1 & 100 & 0 \\
2 & 90 & 10 \\
3 & 80 & 20 \\
4 & 70 & 30 \\
5 & 60 & 40 \\
6 & 50 & 50 \\
\hline
\end{tabular}


buckling, de-lamination, wrong laying of the fibre. Specimens were completely wiped dry in order to remove surface moisture (moisture absorption subjected specimen) before weighing. Cut edge surfaces were also sealed to avoid the water uptake through the fibre broken region for moisture absorption test ${ }^{[6-8]}$.

\section{Experimental Methodology}

\subsection{Moisture absorption characterization}

Water absorption test was performed according to the ASTM D570 standard, by immersing the various test specimens in distilled water at room temperature for twelve months for various temperatures $\left(45^{\circ} \mathrm{C}, 55^{\circ} \mathrm{C}, 65^{\circ} \mathrm{C}\right)$. In order to examine the moisture absorption behavior of the composite pipe, the weight gain of the composite specimens were measured with a precision of $1 \mathrm{mg}$ repeatedly over the immersion period. The percentage weight gain at any time as a effect of moisture absorption was determined by the Equation (1):

$$
\mathrm{M}_{\mathrm{t}}=\frac{\mathrm{W}_{\mathrm{w}-}-\mathrm{W}_{\mathrm{d}}}{\mathrm{W}_{\mathrm{d}}} \times 100(\%)
$$

Where $\mathrm{W}_{\mathrm{w}}$ and $\mathrm{W}_{\mathrm{d}}$ denotes weight of the specimen in wet condition and dry condition respectively, with respect to time t. To calculate the moisture diffusion process in polymer matrix composite pipes, the Fick's law was acceptable one to demonstrate the diffusivity. The same equation was used to identify the moisture uptake in composite pipes, as well the following solution was considered as the viable one.

$$
\frac{M_{t}}{M_{m}}=1-\frac{8}{\pi^{2}} \sum_{n=0}^{\infty} \frac{1}{(2 n+1)^{2}} \exp \left(\frac{-(2 n+1)^{2} \pi^{2} D t}{h^{2}}\right)
$$

Where Mt and Mm are the percentage of the absorbed moisture at time $t$ and the saturation stage respectively, ' $h$ ' is considered as the thickness of the specimen and D is the diffusion coefficient. The diffusion coefficient can be calculated by drawing the curve of the test specimens' weight gain versus the square root of aging time, through the slope of the initial linear region of the curve. The value of $\mathrm{D}$ can be calculated with help of the following equation ${ }^{[16]}$.

$$
\mathrm{D}=\pi \cdot\left(\frac{\mathrm{h}}{4 \mathrm{M}_{\mathrm{m}}}\right)^{2}\left(\frac{\mathrm{M}_{2}-\mathrm{M}_{1}}{\sqrt{\mathrm{t}_{2}}-\sqrt{\mathrm{t}_{1}}}\right)^{2}
$$

\subsection{Burst strength test}

The length, thickness and inner diameter of the specimens were maintained as $300 \mathrm{~mm}, 3 \mathrm{~mm}$, and $124 \mathrm{~mm}$ respectively. One end of the test specimen was completely sealed where as another end was provided with nozzle at end of the pipe.

To do the burst test, first the aged specimen as shown in Figure 3(a) was completely filled with water in order to generate the hydrostatic pressure inside the test specimen. By the way, the burst pressure was calculated by constantly increasing the pressure inside the tube. To maintain safety for the doer all the tests were conducted under the closed environment condition as shown in Figure 3(b). As well to find out the outdoor exposure, the pipe was filled with water and exposed to hygrothermal environment for the period of 3, 6, 9, 12 months and later pressure was tested ${ }^{[6-8]}$.

\subsection{Hoop strength test}

The specimens' size of the hoop test specimens were maintained as $124 \mathrm{~mm}$ inner diameter, width as $25 \mathrm{~mm}$ and thickness as $3 \mathrm{~mm}$ as shown in Figure 4(a). Five samples for
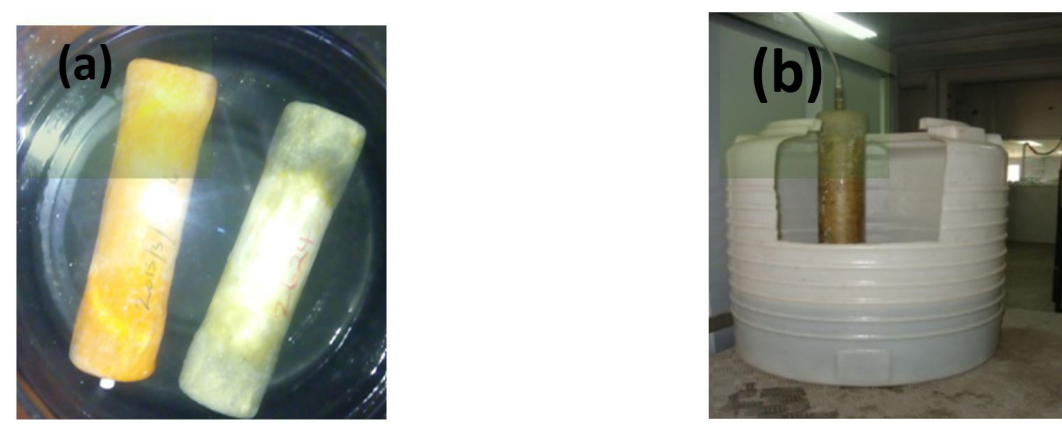

Figure 3. (a) Burst pressure test specimens (b) Specimen in connector \& placed in closed location.
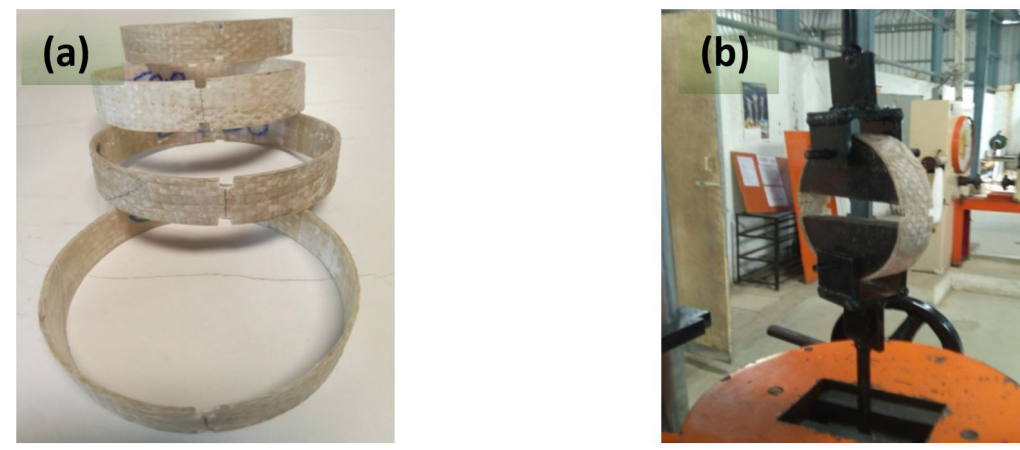

Figure 4. (a) shaped specimens (before test) (b) specimen in ring test kit. 
each (Ring test specimens) proportion ( $0 \% \mathrm{PU}, 10 \% \mathrm{PU}, 20 \% \mathrm{PU}$, $30 \% \mathrm{PU}, 40 \% \mathrm{PU}$ and $50 \% \mathrm{PU}$ ) were randomly selected and immersed in water at elevated temperatures of $45^{\circ} \mathrm{C}, 55^{\circ} \mathrm{C}$ and $65^{\circ} \mathrm{C}$ well below the service temperature of the matrix. As similar to that of the burst test all the specimens were tested (ageing test) at equal intervals like 3, 6, 9, 12 months respectively. The testing was performed as per the ASTM D2290 standard. The hoop test was conducted on mechanically driven test equipment with $100 \mathrm{kN}$ capacity. The feed was maintained as $5 \mathrm{~mm} / \mathrm{min}$. As shown in the Figure 4(b), the inner steel half disks were used to load the specimens. After the test, the fractured surfaces of the specimens were analyzed by visual inspection to indentify the mode of failure. All the samples were weighed before and after immersion ${ }^{[6-8]}$.

\section{Results and Discussion}

\subsection{Characteristics of GFRP IPN pipe specimen in water}

When the composite is immersed in the fluid medium and maintained at various temperatures for different time period; the matrix material (resin) in the composite should not get detach from the fibre and react with the fluid medium. The moisture absorption of the different proportions $(0 \% \mathrm{PU}, 10 \% \mathrm{PU}, 20 \% \mathrm{PU}, 30 \% \mathrm{PU}, 40 \% \mathrm{PU} \&$ $50 \% \mathrm{PU}$ ) specimen graphs were plotted with the square root of day as $\mathrm{X}$ axis, against the various moisture absorption level as $\mathrm{Y}$ axis. The similar kind of graphs were plotted for various temperatures like $45^{\circ} \mathrm{C}, 55^{\circ} \mathrm{C}$ and $65^{\circ} \mathrm{C}$ as shown in Figures 5(a) to 5(b).
From the graph of $0 \% \mathrm{PU}(100 \% \mathrm{VER})$, it can be seen that during the initial time of study for all the proportions ( 5 samples), the specimen's moisture intake was very high with respect to all the temperature variations, includes of $45^{\circ} \mathrm{C}, 55^{\circ} \mathrm{C}$ and $65^{\circ} \mathrm{C}$. In this context as shown in graph when the temperature of water increases, the specimen absorbs more water than the specimens maintained at room temperature. The specimens maintained at $55{ }^{\circ} \mathrm{C}$ was found to absorb $27.58 \%$ higher than $45^{\circ} \mathrm{C}$ specimen during the initial period of time. Similarly the specimen maintained at $65^{\circ} \mathrm{C}$ exhibited a similar trend. The $65{ }^{\circ} \mathrm{C}$ kept specimen absorbs $21.62 \%$ of moisture higher than that of the $55{ }^{\circ} \mathrm{C}$ kept specimens. As the square root of day increased the moisture intake or absorption level got saturated. During the period of $\sqrt{7}$ days the variation found between the $45{ }^{\circ} \mathrm{C}$ to $55{ }^{\circ} \mathrm{C}$ was $12.95 \%$. Similarly the variation between $65^{\circ} \mathrm{C}$ to $55^{\circ} \mathrm{C}$ was $20.57 \%$, this was quite high as compared to the variation between $45^{\circ} \mathrm{C}$ to $55^{\circ} \mathrm{C}$. Whereas during the $\sqrt{ } 19$ the moisture absorption level got almost saturated and there was no variation between the $\sqrt{ } 18$ and $\sqrt{ } 19$ days. Similarly when we consider the uptake of the moisture level during the initial days it was found to be $0.105 \%$, of total weight. Also the graph depicts that for $55{ }^{\circ} \mathrm{C}$ the moisture level was $0.145 \%$. All the values were found to be higher for short span of time for $\sqrt{7}$. This shows that the temperature rise in the water plays a major role in due respect of absorption peaks in all the specimens. But it gradually decreases and almost gets saturated to the downtrodden level irrespective of temperature when it reaches the level of $\sqrt{ } 19$ days. From the Figure 5 revealed that all
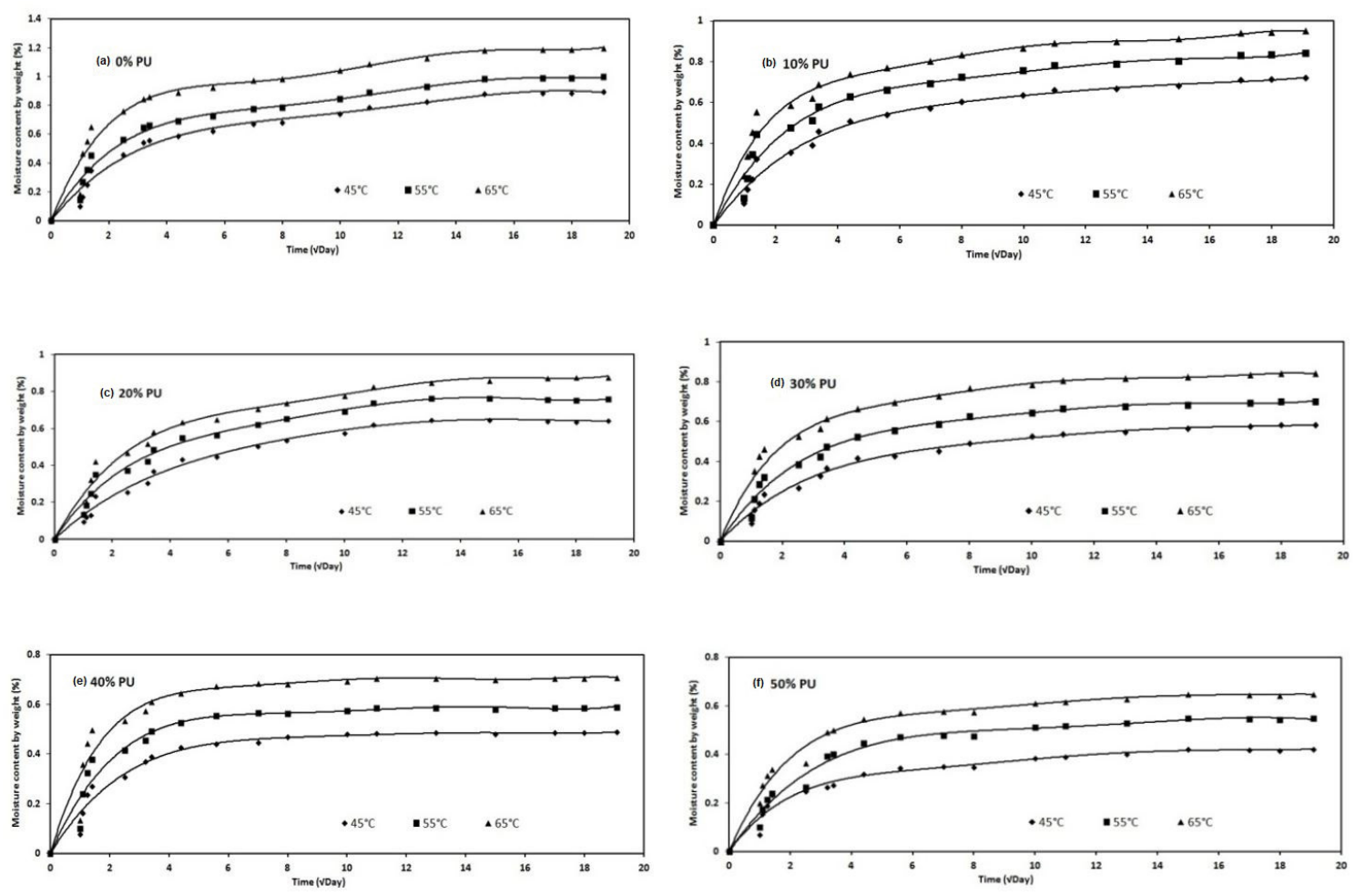

Figure 5. Water absorption curves of specimens (a) $0 \% \mathrm{PU}$, (b) $10 \% \mathrm{PU}$, (c) $20 \% \mathrm{PU}$, (d) $30 \% \mathrm{PU}$, (e) $40 \%$, (f) $50 \%$ PU. 
the specimens shown good agreement between the data and the theory, because all the proportionate graphs follows the Fick's behavior. It was found that $45^{\circ} \mathrm{C}$ absorbs only $0.92 \%$ of its total weight with the corresponding diffusion coefficient of $1.8124 \times 10^{-6}\left(\mathrm{~m}^{2} / \mathrm{s}\right)$, similarly the $55^{\circ} \mathrm{C}$ specimens absorbs $1 \%$ of total weight with the corresponding diffusion coefficient of $2.9543 \times 10^{-6}\left(\mathrm{~m}^{2} / \mathrm{s}\right)$, whereas the $65^{\circ} \mathrm{C}$ absorbs $1.2 \%$ of total weight with diffusion coefficient of $4.1232 \times 10^{-6}\left(\mathrm{~m}^{2} / \mathrm{s}\right)$. The diffusion coefficient as well shows much difference, this was completely based upon the increase in temperature of boiling water. As diffusion increases it leads to much weight again on the specimens. From the Table 2 it was proven that diffusion coefficient is directly proportional to the moisture gain of the IPN system. This actually shows that the temperature played a major factor for all the moisture absorption studies.

Whereas the $10 \%$ PU specimens exhibited a different trend from that of the $0 \% \mathrm{PU}$ specimens. During the initial period of time, it absorbs $(20.45 \%)$ or intake more water than that of the $0 \%$ PU specimens. But as the square root of days increase, the amount of water intake gets saturated at lower temperature than that of the $0 \%$ PU. During the study of $\sqrt{7}$ days of absorption the absorption value found was $0.57 \%, 0.69 \%, 0.8 \%$ for $45^{\circ} \mathrm{C}, 55^{\circ} \mathrm{C}, 65^{\circ} \mathrm{C}$ respectively. The percentage of variation between this was $17.39 \%$, $13.75 \%$ for $55{ }^{\circ} \mathrm{C}, 65{ }^{\circ} \mathrm{C}$ respectively. The found value was much lower than that of the $0 \% \mathrm{PU}$, and the variation between $0 \% \mathrm{PU}$ to $10 \% \mathrm{PU}$ was $0.102,0.082,0.172$ for $45^{\circ} \mathrm{C}, 55^{\circ} \mathrm{C} \& 65^{\circ} \mathrm{C}$ respectively. It seems that the addition of PU into the IPN system remarkably reduced the water intake in to some extent. Besides that, during the study $\sqrt{ } 19$ days the variation again seemed to be similar as discussed for $\sqrt{7}$ days. The moisture uptake was $0.72(\%), 0.84(\%)$, $0.95(\%)$ of total absorption rate for corresponding $45^{\circ} \mathrm{C}$, $55^{\circ} \mathrm{C} \& 65^{\circ} \mathrm{C}$. The addition of $10 \%$ PU shows significant reduction in moisture absorption. This was mainly because

Table 2. Diffusion coefficient values for corresponding temperatures.

\begin{tabular}{|c|c|c|c|}
\hline \multirow{2}{*}{ Specimens } & Immersion & Diffusion coefficient & \multirow{2}{*}{$\mathbf{M} \infty(\%)$} \\
\hline & Temperature $\left({ }^{\circ} \mathrm{C}\right)$ & $\left(\mathrm{m}^{2} / \mathrm{s}\right)$ & \\
\hline \multirow[t]{3}{*}{$0 \% \mathrm{PU}$} & 45 & $1.8 \pm 0.5 \times 10^{-6}$ & 0.92 \\
\hline & 55 & $2.9 \pm 0.8 \times 10^{-6}$ & 1.00 \\
\hline & 65 & $4.1 \pm 0.9 \times 10^{-6}$ & 1.20 \\
\hline \multirow[t]{3}{*}{$10 \% \mathrm{PU}$} & 45 & $5.4 \pm 0.2 \times 10^{-7}$ & 0.72 \\
\hline & 55 & $6.7 \pm 0.9 \times 10^{-7}$ & 0.84 \\
\hline & 65 & $7.7 \pm 0.3 \times 10^{-7}$ & 0.95 \\
\hline \multirow[t]{3}{*}{$20 \% \mathrm{PU}$} & 45 & $6.3 \pm 0.4 \times 10^{-8}$ & 0.64 \\
\hline & 55 & $7.8 \pm 0.8 \times 10^{-8}$ & 0.76 \\
\hline & 65 & $9.1 \pm 0.7 \times 10^{-8}$ & 0.88 \\
\hline \multirow[t]{3}{*}{$30 \% \mathrm{PU}$} & 45 & $7.3 \pm 0.4 \times 10^{-9}$ & 0.58 \\
\hline & 55 & $8.8 \pm 0.6 \times 10^{-9}$ & 0.70 \\
\hline & 65 & $10.2 \pm 0.3 \times 10^{-9}$ & 0.84 \\
\hline \multirow[t]{3}{*}{$40 \% \mathrm{PU}$} & 45 & $8.2 \pm 0.2 \times 10^{-10}$ & 0.48 \\
\hline & 55 & $9.9 \pm 0.3 \times 10^{-10}$ & 0.59 \\
\hline & 65 & $10.5 \pm 0.1 \times 10^{-10}$ & 0.71 \\
\hline \multirow[t]{3}{*}{$50 \% \mathrm{PU}$} & 45 & $7.4 \pm 0.6 \times 10^{-11}$ & 0.42 \\
\hline & 55 & $8.5 \pm 0.4 \times 10^{-11}$ & 0.55 \\
\hline & 65 & $9.8 \pm 0.7 \times 10^{-11}$ & 0.65 \\
\hline
\end{tabular}

of the PU prepolymer addition into VER system. As far as the diffusion coefficient study concerned, the Table 2 showed $5.4537 \times 10^{-7}\left(\mathrm{~m}^{2} / \mathrm{s}\right), 6.7654 \times 10^{-7}\left(\mathrm{~m}^{2} / \mathrm{s}\right), 7.7654 \times 10^{-7}\left(\mathrm{~m}^{2} / \mathrm{s}\right)$ for the corresponding temperature of $45^{\circ} \mathrm{C}, 55^{\circ} \mathrm{C} \& 65^{\circ} \mathrm{C}$ respectively. Again it proves that the moisture absorption was directly proportional to the water temperature. The $20 \% \mathrm{PU}$ showed a similar trend as that of $0 \%$ and $10 \%$ PU systems. The difference of moisture absorption percentage was $26.7 \%$ for initially. However for $\sqrt{7}$ days the difference of variations were $18.38-12.6 \%$ respectively.

At last $6.3876 \times 10^{-8}\left(\mathrm{~m}^{2} / \mathrm{s}\right), 7.8745 \times 10^{-8}\left(\mathrm{~m}^{2} / \mathrm{s}\right) \&$ $9.1652 \times 10^{-8}\left(\mathrm{~m}^{2} / \mathrm{s}\right)$ respectively $\left(45^{\circ} \mathrm{C}, 55^{\circ} \mathrm{C} \& 65^{\circ} \mathrm{C}\right)$ for the corresponding $(20 \% \mathrm{PU})$ water temperatures. The PU prepolymer addition into VER system again proved that there was a significant reduction of water absorption for all the specimens. This can be proved from the absorption percentage of $0.64,0.76 \& 0.88 \%$ respectively for the corresponding temperatures. This shows the $80 \%$ of VER present into the IPN system absorbs the much moisture as compared with the remaining $20 \%$ of PU. For $50 \%$ PU, the diffusion coefficient was $7.4863 \times 10^{-11}\left(\mathrm{~m}^{2} / \mathrm{s}\right), 8.5432 \times 10^{-11}\left(\mathrm{~m}^{2} / \mathrm{s}\right) \& 9.8745 \times 10^{-11}\left(\mathrm{~m}^{2} / \mathrm{s}\right)$ with the corresponding moisture gain of $0.42,0.55 \& 0.65 \%$ for the water temperature of $45^{\circ} \mathrm{C}, 55^{\circ} \mathrm{C} \& 65^{\circ} \mathrm{C}$. From these values, it can be concluded that that with increase in PU prepolymer content in IPN systems the moisture absorption was found to decrease.

\subsection{Influence of water absorption (diffusion) on hoop strength}

In general, all the engineering products require good and reliable mechanical properties, even after exposure to various hygrothermal environments like temperature, pressure and moisture etc. This is also applicable for composite pipes, which are mostly known to be used under high temperature and moist environments. Hence their mechanical property was studied under artificially created hygrothermal conditions, where as the dry specimens without hygrothermal ageing, have shown the hoop strength of $95.49,91.15,84.64,77.69,69.40,60.33 \mathrm{MPa}$ of strength for respective proportions ${ }^{[7]}$. In the study the mechanical behavior of (hoop strength) IPN pipes when subjected to hygrothermal (pertains to moisture and heat) condition was studied. The Hoop strength for different proportions of PU (0\%PU, 10\%PU, 20\%PU, 30\%PU, 40\%PU \& 50\%PU) loaded pipes after moisture ageing treatment are shown in Figure 6. The overall view obtained from the study is that, increase in temperature decreases the Hoop strength of the IPN pipes. While considering the $0 \% \mathrm{PU}$ loaded pipe the hoop strength showed a decrease with hygrothermal ageing. The hoop strength of the pipe showed a decrease of $16 \%$ compared with the specimens exposed to water at $45^{\circ} \mathrm{C}$ for 3 and 6 months. A similar trend is also depicted in PU loaded pipes. For the PU loaded pipes, increase in PU content caused a decrease in the Hoop stress. In addition, exposures to various $\left(45^{\circ} \mathrm{C}, 55^{\circ} \mathrm{C} \& 65^{\circ} \mathrm{C}\right)$ temperatures with different time period also cause a decrease in hoop stress. On considering the $30 \% \mathrm{PU}$ loaded pipe, the dry specimen had the hoop strength value of $77.7 \mathrm{MPa}^{[6]}$, specimen exposed to temperature of $55^{\circ} \mathrm{C}$ had the value of $63 \mathrm{MPa}$ for 90 days. 

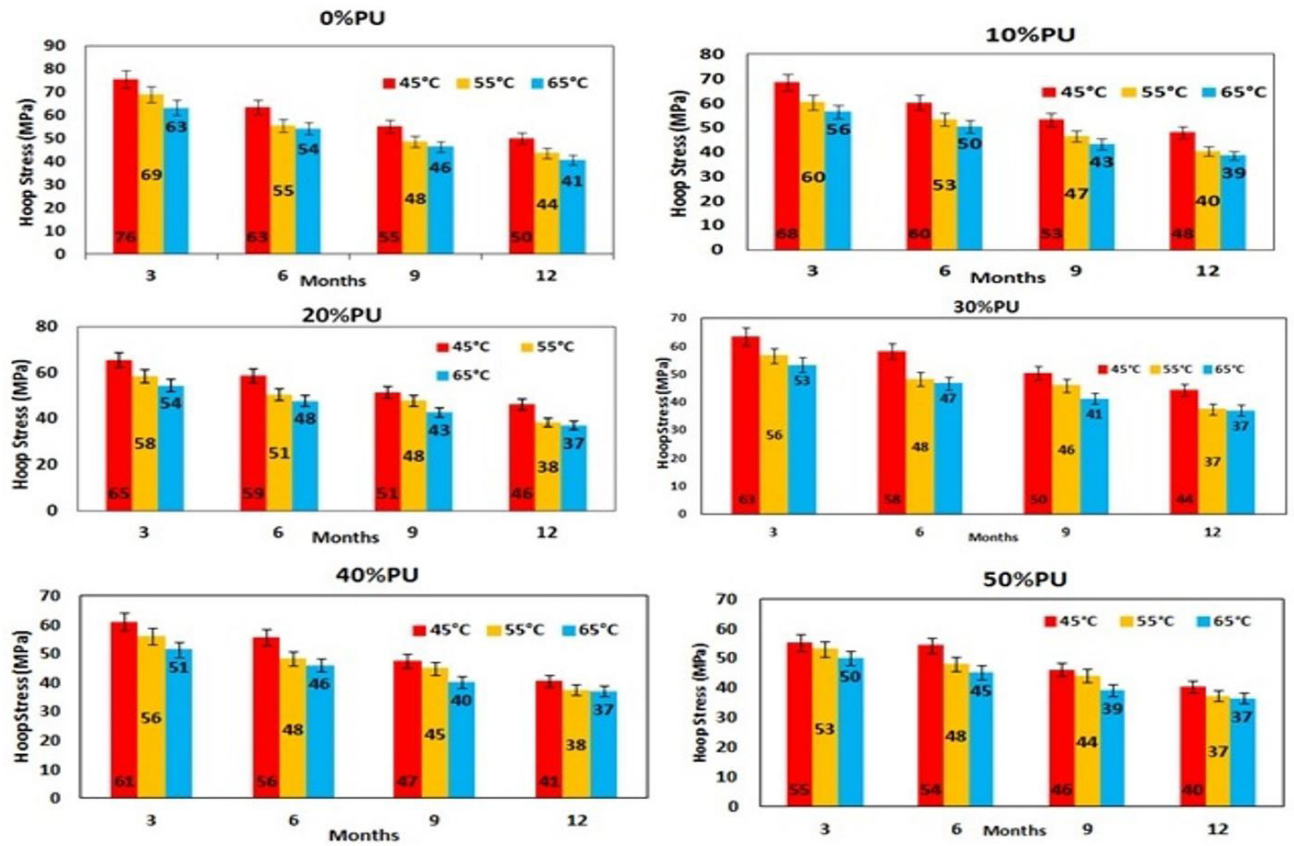

Figure 6. Ring test results after water boiling treatment of $0 \%, 10 \%, 20 \%, 30 \%, 40 \%, 50 \%$ PU loaded IPN composite pipe.
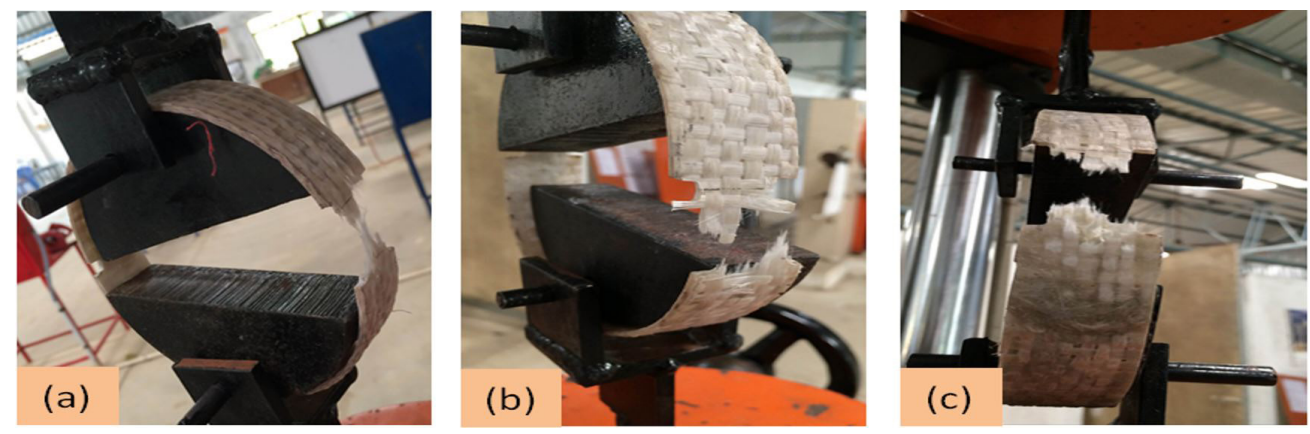

Figure 7. Ring test (Hoop test) specimens after test (a) $45^{\circ} \mathrm{C}$ (b) $55^{\circ} \mathrm{C}$ (c) $65^{\circ} \mathrm{C}$.

Subsequently the decline of hoop stress was noted as $58 \mathrm{MPa}$ for 180 days and $44 \mathrm{MPa}$ for 270 days. This showed that, the exposure to high temperature weakens the bond in between the fibre and matrix system causing fracture at reduced loads. At $65{ }^{\circ} \mathrm{C}$ of $50 \%$ PU loaded IPN composite pipe shown very lower moisture absorption. The corresponding diffusion (Table 2) coefficient value of $65{ }^{\circ} \mathrm{C}(50 \%$ PU) also comparatively very less as similar to that of the remaining proportionate of IPNs. When the same specimen subjected to hoop strength, the stress value was $37 \mathrm{MPa}$. This phenomenon was due to the plasticizing effect of PU (soft segment), which lost its shear force with VER (hard segment) at higher temperature. It was found that, fibre/resin binding was completely disturbed in the fractured specimens this was because of leathery state of the polyurethane at considerable temperature[. The fracture was mainly because of fibre/matrix interface debonding. During the hygrothermic test, water penetrates into the interface region through the micro voids and the micro cracks present in the specimen. This trapped water partially damages the interface region. This leads to fibre breakage in most of the specimens as dominant failure mode. Figure 7. Clearly shows the fibre pullout phenomenon of all the specimens in various temperatures. This was the main failure mode in all the specimens irrespective of the temperature. Similarly the effect of the temperature was key phenomenon for all the matrix degradation, thus the way; the matrix degradation was the evident for the early failure during the test.

Surprisingly the another notable study was found during this research, that was, as much as the PU loading is increased into the system, it remarkably reduces the diffusion coefficient to the much higher stage, by the way it decreases the moisture absorption value to the higher stages. Form the diffusion table, it can be very clearly seen. As we discussed, the difference of hoop strength between the dry to the PU loaded specimen reduces as we increase the PU loading into the IPN system. Besides that, the moisture absorption characteristics were limited to the boiling water 
aged (PU loading) specimens while comparing with the pure VER made specimens. Figure 8 completely describes the TGA value of the IPNs after the hygrothermal ageing test. From the Figure 8, it was observed that PU loaded VER IPN have had an very lesser thermal stability as compared with the pure VER system.

The onset of degradation for $0 \% \mathrm{PU}$ system was $365^{\circ} \mathrm{C}$. With increasing PU content from $10 \%$ to $50 \%$, there was a gradual and steady decrease in thermal stability from $300{ }^{\circ} \mathrm{C}$ to $200{ }^{\circ} \mathrm{C}$. Irrespective of PU loading the IPN system exhibited a maximum degradation temperature around $410{ }^{\circ} \mathrm{C}$ after ageing. The reason behind this degradation was that, the breakage of the interchain bond by the gain of the water into the polymer, this phenomenon results the increase in mobility of the macromolecular this leads to the decrease in the TGA after the hygrothermal test.

\subsection{Influence of moisture on burst pressure}

Burst pressure test also known as hydrostatic pressure test was performed under room temperature as per ASTM D1599 Standard. The PU loaded IPN composite test specimens were immersed in the de-ionized water for various period of time e.g. 3, 6, 9 and 12 months and then tested for burst pressure. The initial pure virgin dry sample was tested, and the value was found to be 25.5 bar $(2.55 \mathrm{MPa})^{[6]}$. With increase in ageing period the burst pressure showed a decreasing trend, due to the absorbed moisture. The values obtained through burst pressure test after moisture absorption were recorded and plotted in Figure 8 . The $0 \% \mathrm{PU}$ in the figure showed a nominal decrease in the value of burst pressure during the first 3 months. After 3 months exposure period, the percentage decrease to be $15.7 \%$. This drastic drop in burst pressure might be due to of the absorption of moisture. After 6 to 9 months, there is no significant change in the burst pressure values. There was a minor increase in the value of the burst pressure at 12 month exposure period, which was considered as saturation point. When the $(0 \% \mathrm{PU})$ dry specimen comes across the burst test, known that, there was proper bonding as well adhesion between the matrix and the fibre, but when it exposed to certain humid condition there was degradation of fibre-matrix interface. Similarly when the ageing time increases, the significant reduction of resin around the fibre leading to weakening the fibre-matrix interface. Various proportions of PU loaded glass fibre reinforced VER IPN composites were subjected to burst pressure test and the values obtained were plotted and compared with the $0 \%$ PU pipe as in the Figure 9.

A similar trend was observed for all the proportions (10\%PU, 20\%PU, 30\%PU, 40\%PU \& 50\%PU). For 10\%PU it was observed that, the burst pressure decreased greatly for the first 3 month exposure period to moisture. The values at 6 and 9 month exposure period showed a marginal difference in the value with a decrease of $2.6 \%$. The similar trend was not seen in 12 months, because no significant change in the values. The 12 month period had a percentage increase of $0.52 \%$ in burst pressure. The values of burst pressure for $0 \% \mathrm{PU}$ and $10 \% \mathrm{PU}$, only has a small change in the burst pressure, showing that the moisture absorption in the pipes were similar. Comparing the pipes of other compositions for burst pressure against moisture absorption,

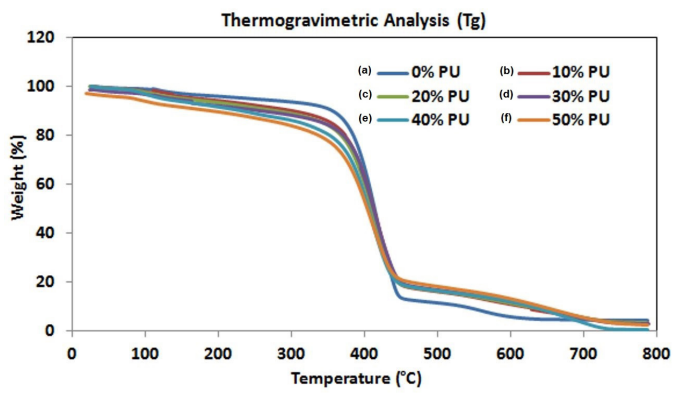

Figure 8. TGA Curve of IPNs (a) $0 \% \mathrm{PU}$, (b) $10 \% \mathrm{PU}$, (c) $20 \% \mathrm{PU}$, (d) $30 \% \mathrm{PU}$, (e) $40 \% \mathrm{PU}$, (f) $50 \% \mathrm{PU}$ (After Hygrothermal Ageing Test).

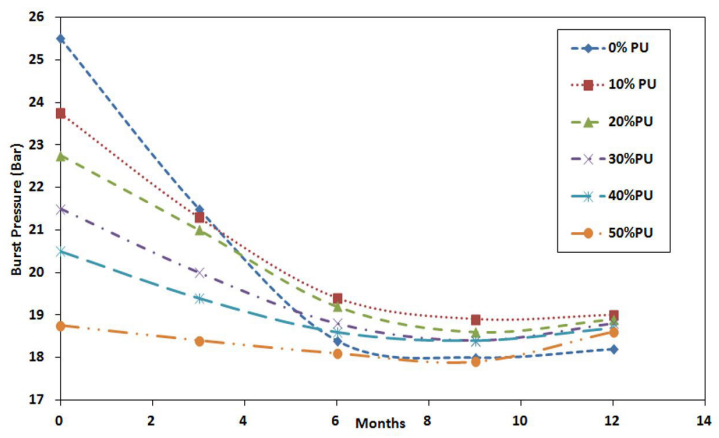

Figure 9. Burst strength analysis of different proportion of IPN composite pipe.

the values for $20 \% \mathrm{PU}$ had a decrease in the percentage from $7.69 \%-3.12 \%$ for 3 to 9 months. For $10 \%$ PU, the value was steadily maintained for 12 months as well. In $30 \% \mathrm{PU}, 40 \% \mathrm{PU}, 50 \% \mathrm{PU}$ the percentage reduction in the values of burst pressure for moisture absorbed pipes were similar and had a slight change with percentage differences from $4 \%$ to $1.1 \%$ for 3 to 9 months, whereas the pipes with exposure period of 12 month showed slight increase in percentage of burst pressure from $1.6 \%$ to $2.5 \%$. Figure 9 shows that, the moisture absorption characteristic abruptly decreases the burst pressure for all the proportions for the corresponding immersion period of 3 to 9 months. The values on burst pressure and moisture absorption have not shown any significant changes for the remaining period up to 12 months. In addition to this, the significant observation was that, the PU loaded VER pipes showed very less effect to moisture absorption because PUs offers good resistance against moisture absorption.

\section{Conclusions}

The following observations were drafted from the experimental analysis. Hygrothermal behavior of Glass fibre reinforced IPN composite pipe was studied for different proportions ( $0 \%$ PU, 10\%PU, 20\%PU, 30\%PU, 40\%PU \& $50 \%$ PU) by subjecting the pipe at $45^{\circ} \mathrm{C}, 55^{\circ} \mathrm{C} \& 65^{\circ} \mathrm{C}$ in water testing chamber for a maximum duration of 365 days. The maximum moisture uptake eventually reduced the mechanical properties of the GFRP pipes, when the specimens 
were subjected to tests like Burst pressure test, Hoop strength test. From the study it was observed that, the plasticization effect of resin material created the de-bonding effect between the fibre and matrix. This effect was very common phenomenon for all the composite pipes. Besides that, the diffusion coefficient was evaluated for all the composition. The diffusion coefficients with their corresponding moisture uptake was that, the $0 \% \mathrm{PU}$ gains $1.2 \%$ of weight $\%$, towards the corresponding diffusion coefficient of $4.1232 \times 10^{-6}$ at the water temperature of $65{ }^{\circ} \mathrm{C}$. Eventually for $50 \% \mathrm{PU}$, significant achievement of $0.65 \%$ of moisture gain was seen for the corresponding temperature of $65^{\circ} \mathrm{C}$. This was due to the loading of PU into the VER system. Whereas the same parameter was very high for neat resin E-glass fibre reinforced composite pipes. It was found that the moisture absorption increased with increase of temperature for all the proportions. In the contrary, PU loaded specimens were found to be superior ones as far as the moisture absorption behavior concerned.

\section{References}

1. Al-Sulaiman, F., Khan, J., Merah, N., Kounain, M. A., \& Mehdi, M. (2010). Effects of weathering on failure pressure of filamentwound GFRP thermoset pipes. Journal of Composite Materials, 45(6), 645-655. http://dx.doi.org/10.1177/0021998310377933.

2. Chang, D. J. (2003). Burst tests of filament-wound graphiteepoxy tubes. Journal of Composite Materials, 37(9), 811-882. http://dx.doi.org/10.1177/002199803031032.

3. Yao, J., \& Ziegmann, G. (2007). Water absorption behavior and its influence on properties of GRP Pipe. Journal of Composite Materials, 41(8), 993-1008. http://dx.doi. org $/ 10.1177 / 0021998306067265$.

4. Ghorbel, I. (1995). Durability of closed-end pressurized GRP Filament wound pipes under hygrothermal aging conditions. Part II: creep Tests. Journal of Composite Materials, 30(14), 1581-1595. http://dx.doi.org/10.1177/002199839603001404.

5. Shahram, E., Abbas, H. R., \& Shiva, E. (2015). Effects of moisture absorption on degradation of E-glass fiber reinforced Vinyl Ester composite pipes and modelling of transient moisture diffusion using finite element analysis. Corrosion Science, 90(1), 168-175.

6. Suresh, G., Jayakumari, L. S., \& Dinesh, K. S. (2017). Finite element analysis of IPN reinforced woven fabric composite. Revistamateria, 22(4), 1-6. http://dx.doi.org/10.1590/s1517707620170004.0216.

7. Suresh, G., \& Jayakumari, L. S. (2016). Analyzing the mechanical behavior of E-glass fibre reinforced interpenetrating polymer network composite pipe. Journal of Composite Materials, 50(22), 3053-3061. http://dx.doi.org/10.1177/0021998315615408.

8. Lima Sobrinho, L., Ferreira, M., \& Bastian, F. L. (2009). The effects of water absorption on an ester vinyl resin system. Materials Research, 12(3), 353-361. http://dx.doi.org/10.1590/ S1516-14392009000300017.

9. Suresh, G., \& Jayakumari, L. S. (2015). Evaluating the mechanical properties of E-Glass fiber/carbon fiber reinforced interpenetrating polymer networks. Polimeros: Ciência e Tecnologia, 25(1), 49-57. http://dx.doi.org/10.1590/01041428.1650 .

10. Guoqiang, L., Su-Seng, P., \& Jack, E. H. (2001). Stiffness degradation of FRP strengthened RC beams subjected to hygrothermal and aging attacks. Journal of Composite Materials, 36(7), 795-812.

11. Wang, G. Y., Wang, Y. L., \& Hu, C. P. (2000). Interpenetrating polymer networks of polyurethane and graft vinyl ester resin: polyurethane formed with toluene diisocyanate. European Polymer Journal, 36(4), 735-742. http://dx.doi.org/10.1016/ S0014-3057(99)00113-5.

12. Cristea, M., Ibanescu, S., Cascaval, C. N., \& Rosu, D. (2009). Dynamic mechanical analysis of polyurethane-epoxy interpenetrating polymer networks. High Performance Polymers, 21(5), 608-623. http://dx.doi.org/10.1177/0954008309339940.

13. Fan, L. H., Hu, C. P., \& Ying, S. K. (1996). Thermal analysis during the formation of polyurethane and vinyl ester resin interpenetrating polymer networks. Polymer, 37(6), 887-1058. http://dx.doi.org/10.1016/0032-3861(96)87280-6.

14. Qin, C. L., Cai, W. M., Cai, J., Tang, D.-Y., Zhang, J.-S., \& Qin, M. (2004). Damping properties and morphology of polyurethane/vinyl ester resin interpenetrating polymer network. Materials Chemistry and Physics, 85(3), 402-409. http://dx.doi.org/10.1016/j.matchemphys.2004.01.019.

15. Mezghani, K. (2012). Long term environmental effects on physical properties of Vinylester composite pipes. Polymer Testing, 31(1), 76-82. http://dx.doi.org/10.1016/j.polymertesting.2011.10.001.

16. Feih, S., Mathys, Z., Mathys, G., Gibson, A. G., Robinson, M., \& Mouritz, A. P. (2008). Influence of water content on failure of phenolic composites in fire. Polymer Degradation \& Stability, 93(2), 376-382. http://dx.doi.org/10.1016/j. polymdegradstab.2007.11.027.

17. Suresh, G., Abdul Munaf, A., Akash, R. M., Bharani Kumar, S., \& Kanagaraja, K. (2019). Analyzing the mechanical behaviour of carbon fiber reinforced spur gear with IPN as matrix material. $\operatorname{SSRN}, 1(11), 1-4$.

Received: Sept. 24, 2018

Revised: July 26, 2019

Accepted: Aug. 01, 2019 